\title{
Determination of Certain Amino-acids by Ninhydrin Oxidation to Volatile Aldehydes
}

\author{
By A. I. VIRTANEN aNd N. RAUTANEN, Biochemical Institute, Helsinki
}

(Received 19 July 1946)

The quantitative determination of amino-acids in a small sample is an important aim in protein research in its present stage. Especially in the U.S.A. and in Great Britain great advances have been made in this field during recent years. In this connexion the lecture by Chibnall (1946) may be cited. Nevertheless, the elucidation of the amino-acid composition of proteins is still a difficult task and uncertainty is continuously met with in regard to the results. Investigations in which analysis should be repeated at short intervals, as is the case, for instance, when protein synthesis in plants is examined, are almost impossible to perform for technical reasons. Rapid and easily applicable methods for the determination of amino-acids are still lacking.

Oxidation of amino-acids by ninhydrin evolves carbon dioxide as noted by Ruhemann (1911) and by Grassmann \& von Arnim (1934). Van Slyke \& Dillon (1936, 1938) and Mason (1937, 1938) found that the carboxyl group is thereby split off quantitatively. On the basis of this finding they developed a manometric method for the quantitative determination of the carboxyl group in amino-acids.

In this laboratory we have examined the aldehydes which are formed as the other oxidation product in the ninhydrin oxidation of amino-acids. Already before the war we had considered the possibility of determining aliphatic monoaminomonocarboxylic acids by means of volatile aldehydes $\left(R . \mathrm{CH}\left(\mathrm{NH}_{2}\right) \cdot \mathrm{COOH} \rightarrow R . \mathrm{CHO}\right)$ formed through the action of ninhydrin. It was found that alanine, valine, leucine and its isomers, phenylalanine and methionine quantitatively form the corresponding aldehydes (acetaldehyde, isobutylaldehyde, isovaleraldehyde, methylethylaldehyde, phenylaldehyde and methylethylaldehyde, phenylaldehyde and methylthiopropionaldehyde) which, being volatile, can easily be separated from the reaction mixture and fixed with bisulphite solution. The method based on this principle was developed for determination of the said group of amino-acids (Virtanen \& Laine, $1938 a, b$; Virtanen, Laine \& Toivonen, 1940), which is otherwise difficult to determine.

We have now re-examined this method, developed further its accuracy and removed one source of error. The method in its present form is described below (cf. Virtanen \& Rautanen, 1946).

\section{EXPERIMENTAL}

Previously we determined the said group of amino-acids (then named 'aldehyde-amino-acids', a more appropriate name is 'volatile aldehyde amino-acids') by means of steam distillation whereby the aldehydes were collected in bisulphite solution in a U-tube connected to the end of the condenser. As some bisulphite-fixing substance is also formed from aspartic acid, we first removed aminodicarboxylic acids from the protein hydrolysate by a Foreman precipitation, and only after that carried out the ninhydrin oxidation.

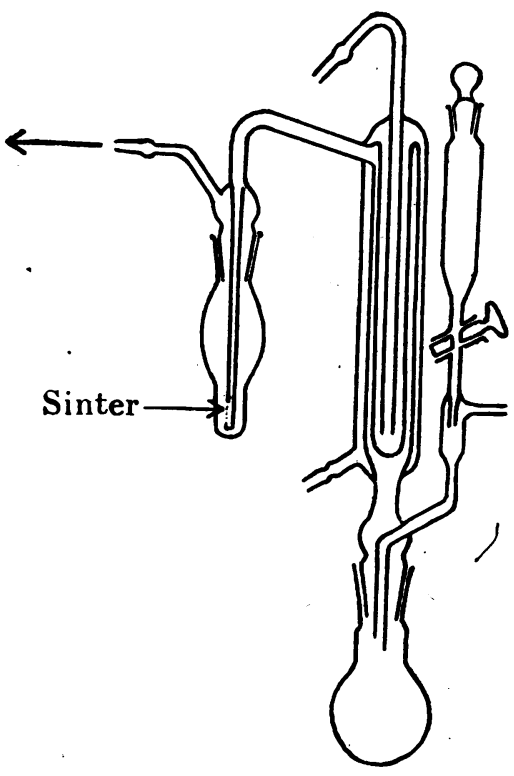

Fig. 1. Lieb-Zacherl apparatus used in determinations of volatile aldehydes formed from amino-acids.

In further development of the method we have used, instead of steam distillation, the apparatus devised by Lieb \& Zacherl (1932) for lactic acid determination (Fig. 1). Volatile aldehydes are thereby sucked by a current of air from the reaction flask into the receiver and the evaporation of water vapour is prevented to a great extent by effective cooling. In the previous papers only acetaldehyde arising from alanine was determined in this apparatus, since its separation from higher aldehydes formed from other aminoacids was thought possible. This is not the case, however. According to our later determinations the separation of 
acetaldehyde from other aldehydes is not possible by this method. On the contrary, during a longer reaction time all the aldehydes concerned are quantitatively trapped in the bisulphite solution in the receiver. All "volatile aldehyde amino-acids' can thus be determined in the said apparatus.

The use of the Lieb-Zacherl apparatus for the determination of 'volatile aldehyde amino-acids' has certain advantages over steam distillation, viz. (i) it is not necessary to remove aspartic acid before the analysis; (ii) acetaldehyde and hence alanine can be separately determined (for instance colorimetrically) in the bisulphite solution, the volume of which remains approximately constant. With steam distillation, on the other hand, the volume of bisulphite solution is considerably increased, making it more difficult to determine acetaldehyde separately.

When 'volatile aldehyde amino-acids' are determined in the Lieb-Zacherl apparatus, aldehydes formed from phenylalanine and especially from methionine are distilled slowly and define the distillation time, which depends also on the vigour of the air stream, on the effectiveness of heating and on the length of the condenser tube. Other than 'volatile aldehyde amino-acids' do not give aldehydes which are distilled over into the bisulphite solution, at least not to such an extent as to have any noteworthy effect on the results (cf. the data below).

\section{METHOD}

Two apparatuses were used; the length of the condenser tube was $10 \mathrm{~cm}$. in the one and $12 \mathrm{~cm}$. in the other. The temperature of the cooling water was from 6 to $8^{\circ}$; the flame was adjusted so that boiling was rather vigorous.

Ten ml. of the solution to be investigated, the monoamino-acid content of which corresponds to about $0.05-0.2 \mathrm{mg}$. $\mathrm{N}$, are placed in the reaction flask of the Lieb-Zacherl apparatus, and $1 \mathrm{~g}$. of $\mathrm{KH}_{2} \mathrm{PO}_{4}$ and $2 \cdot 1 \mathrm{~g}$. of $\mathrm{NaCl}$ are added. Ten $\mathrm{ml}$. of $1 \%$ sodium bisulphite are placed in the receiver. $\mathbf{A}$ strong stream of air is sucked through the apparatus, and the solution is brought to the boil over a small flame. Ninhydrin solution $(2 \mathrm{ml}$., the required concentration of ninhydrin is given below) is let from the side tube into the solution, whereupon the level of the surface of the solution is marked with grease pencil on the side of the reaction flask. Distillation is continued for $\mathbf{7 5}$ min., after which the heating is interrupted and the receiver disconnected. The tube with sintered end is washed with water and the bisulphite solution titrated with $0.01 \mathrm{~N}$-iodine solution.

Distillation cannot be continued beyond $75 \mathrm{~min}$. with the same lot of bisulphite solution since sulphur dioxide is removed gradually from the bisulphite solution by the air current. A new lot of bisulphite solution is then placed in the receiver, and the reaction flask made up to the original volume with water via the side tube, after which the operation is repeated for a further $75 \mathrm{~min}$. without further ninhydrin addition. If methionine is present among the amino-acids to be investigated the operation must be repeated a third time for $75 \mathrm{~min}$. After this all volatile aldehydes are removed with certainty. When three successive distillations of $\mathbf{7 5} \mathrm{min}$. are used, variations in the vigour of the air stream and in the size of flame are not nearly so important as when shorter distillation times are used, since in the former case the aldehydes have time to distil over more quantitatively.

In solutions which contain both amino-acids yielding volatile and non-volatile aldehydes, the amount of aldehydes distilled into the bisulphite solution during three periods of $75 \mathrm{~min}$. corresponded to $99-101 \%$ of the 'volatile aldehyde amino-acids' only. When distillation is continued after this, the additional iodine consumption of the bisulphite solution is no greater than in a blank; this shows that aldehydes formed from other amino-acids are not distilled over. Before this method is applied to an unknown solution, it is important to perform a test with a protein hydrolysate of known composition, in analysis with a known mixture of amino-acids in order to find out the appropriate velocity of the air stream and the size of flame.

\section{RESULTS}

The analyses in Table 1 illustrate the accuracy of the method.

Analysis of casein hydrolysate. The application of our method to analysis of casein hydrolysate is illustrated by the four experiments recorded in Table 2.

According to the latest determinations made in the laboratory of Chibnall (1946) the following amounts of the amino-acids in question were found:

$\begin{array}{lc} & \begin{array}{c}\text { Casein } \\ \text { N as \% protein-N }\end{array} \\ \text { Alanine } & 3 \cdot 2 \\ \text { Valine } & 4 \cdot 6 \\ \text { Leucine } & \mathbf{7 \cdot 2} \\ \text { Isoleucine } & 3 \cdot 6 \\ \text { Phenylalanine } & 3 \cdot 5 \\ \text { Methionine } & \mathbf{2 \cdot 1} \\ \quad \text { Total } & \mathbf{2 4 \cdot 2}\end{array}$

The agreement between our values (average $24 \cdot 6$ ) and those of Chibnall (24.2) is good.

\section{The amount of ninhydrin necessary}

As the ninhydrin is an expensive substance we examined more closely with how small an amount of ninhydrin reliable results could still be obtained. If the reaction between ninhydrin and $\alpha$-amino-acid occurs in the way Ruhemann (1911) assumes (see formula on p. 977), the ratio of ninhydrin to amino- $N$ would be $356 / 14$, or $25 \cdot 4$. Thus $0 \cdot 1 \mathrm{mg}$. amino-N would require $2.54 \mathrm{mg}$. ninhydrin. 
<smiles>NC([R]C(O)(O)C(=O)OCc1ccccc1)C(=O)O</smiles>

Triketo-hydrindenhydrate (Ninhydrin)
Our experiments on the effect of varying amounts of ninhydrin upon the results are illustrated by the following examples. The composition of the reaction solution and the experimental conditions were the same as above in all experiments except that the amount of ninhydrin was varied.

(i) $1.0 \mathrm{mg} . \alpha$-alanine $+5 \mathrm{mg}$. ninhydrin (theoretical amount 4.0 $\mathrm{mg}$.). $2 \cdot 16 \mathrm{ml}$. of $0 \cdot 0096 \mathrm{~N}$-iodine solution were used; amino-N found : $92.2 \%$ of the theoretical amount. In a duplicate experiment the yield was $87 \cdot 6 \%$.

(ii) $1.0 \mathrm{mg} . \alpha$-alanine $+7 \cdot 5 \mathrm{mg}$. ninhydrin. $2 \cdot 24 \mathrm{ml}$. of $0.01 \mathrm{~N}$-iodine solution were used; amino- $\mathrm{N}$ found: $99.7 \%$ of the theoretical amount; a duplicate gave $98 \cdot 8 \%$.

(iii) $1.0 \mathrm{mg} . \alpha$-alanine $+10 \mathrm{mg}$. ninhydrin. $2 \cdot 24 \mathrm{ml}$. of $0.01 \mathrm{~N}$-iodine solution were used; amino- $\mathrm{N}$ found : $99.7 \%$ of the theoretical value.

(iv) $1 \mathrm{ml}$. casein hydrolysate ( $=0.474 \mathrm{mg}$. total $\mathrm{N}$ containing $\left.0.314 \mathrm{mg} . \quad \mathrm{NH}_{2}-\mathrm{N}\right)+10 \mathrm{mg}$. ninhydrin (theoretical amount 8.0 mg.). $1.45 \mathrm{ml}$. of $0.01 \mathrm{~N}$-iodine solution were used for lst fraction, $0 \cdot 16 \mathrm{ml}$. for $2 \mathrm{nd}$ fraction and $0.05 \mathrm{ml}$. for $3 \mathrm{rd}$ fraction, total $1.66 \mathrm{ml}$. Found : $0.1162 \mathrm{mg}$. $\mathrm{N}$ of 'volatile aldehyde aminoacids' or $\mathbf{2 4 . 5} \%$ of the total $\mathrm{N}$ in casein.

(v) $1 \mathrm{ml}$. casein hydrolysate $(0.474 \mathrm{mg}$. total $N$ containing $\left.0.314 \mathrm{mg} . \quad \mathrm{NH}_{2}-\mathrm{N}\right)+15 \mathrm{mg}$. ninhydrin. $1.46 \mathrm{ml}$. of $0.01 \mathrm{~N}$-iodine solution were used for lst fraction, $0.13 \mathrm{ml}$. for $2 \mathrm{nd}$ fraction and $0.06 \mathrm{ml}$. for 3rd fraction, total $1.65 \mathrm{ml}$. Found : $0.1155 \mathrm{mg}$. $\mathrm{N}$ of 'volatile aldehyde amino-acids' or $24.4 \%$ of the total $\mathrm{N}$ in casein.

On the basis of the results above it was concluded that a quantity of ninhydrin which is approximately $50 \%$ greater than the theoretical is sufficient for determinations as far as pure amino-acids or a casein hydrolysate are in question. In the experiments recorded in Table 1 we therefore were employing well over three times more ninhydrin than was really necessary.

If the amino-acids are to be determined in solutions which contain sugar, organic acids and other organic substances, as is the case for instance with plant extracts, the amounts of ninhydrin must be somewhat increased. This is illustrated by the following experiments :

(i) $1 \mathrm{mg} \cdot \alpha$-alanine $+20 \mathrm{mg}$. glucose $+7 \cdot 5 \mathrm{mg}$. ninhydrin (theoretical amount $4.0 \mathrm{mg}$.). $2.12 \mathrm{ml}$. of $0.01 \mathrm{~N}$-iodine solution were used; amino-N found: $94.3 \%$ of the theoretical value. (ii) $1 \mathrm{mg} . \alpha$-alanine $+20 \mathrm{mg}$. glucose $+10 \mathrm{mg} . \mathrm{nin}$ hydrin. $2 \cdot 24 \mathrm{ml}$. of $0 \cdot 01 \mathrm{~N}$-iodine solution were used; amino-N found: $99 \cdot 7 \%$ of the theoretical value.

Thus the presence of glucose increased the requirement of ninhydrin to such an extent that an excess of $150 \%$ of ninhydrin was needed for attainment of the proper result. The presence of trichloroacetic acid in the solution also requires that more ninhydrin be used. For example:

(i) $1 \mathrm{mg}$. $\alpha$-alanine $+100 \mathrm{mg}$. trichloroacetic acid $+7.5 \mathrm{mg}$. ninhydrin. $2.11 \mathrm{ml}$. of $0.01 \mathrm{~N}$-iodine solution were used; amino-N found: $93.9 \%$.

(ii) $1 \mathrm{mg}$. $\alpha$-alanine $+100 \mathrm{mg}$. trichloroacetic acid $+10 \mathrm{mg}$. ninhydrin. $2.27 \mathrm{ml}$. of $0.01 \mathrm{~N}$-iodine solution were used; amino-N found: $101.0 \%$.

\section{DISCUSSION}

When an unknown solution is to be examined, which contains amino-acids as well as other organic substances, it is safest to carry out two parallel analyses with different quantities of ninhydrin. In this way the extent can be found to which the increased amount of ninhydrin causes a rise in the aldehydes formed.

In examining yeast and plant extracts we have removed ether-soluble substances by thorough ether extraction before determining 'volatile aldehyde amino-acids', since it has been shown that some acetaldehyde is formed from pyruvic acid under the conditions of our method. Precipitation of aminoacids from the solution would be another means of separating the amino-acids from foreign organic substances; but we have not yet tried this.

With alloxan which, like ninhydrin, also causes the formation of aldehydes from corresponding amino-acids, quantitative results have not been obtained.

In addition to the group of "volatile aldehyde amino-acids' it is possible by our method to determine alanine separately, since acetaldehyde can be estimated in the bisulphite solution beside other aldehydes formed (cf. Roine, 1946). If phenylalanine and methionine are determined by other methods in protein hydrolysates, the aldehydes formed by them and alanine can be calculated and subtracted from the total amount of aldehydes. Thus valine + leucine + isoleucine are left over. We have not yet succeeded in developing a method for the separate determination of the aldehydes formed from these amino-acids. 
Table 1. Determination of 'volatile aldehyde amino-acids' separately, as groups, and in mixtures of other amino-acids

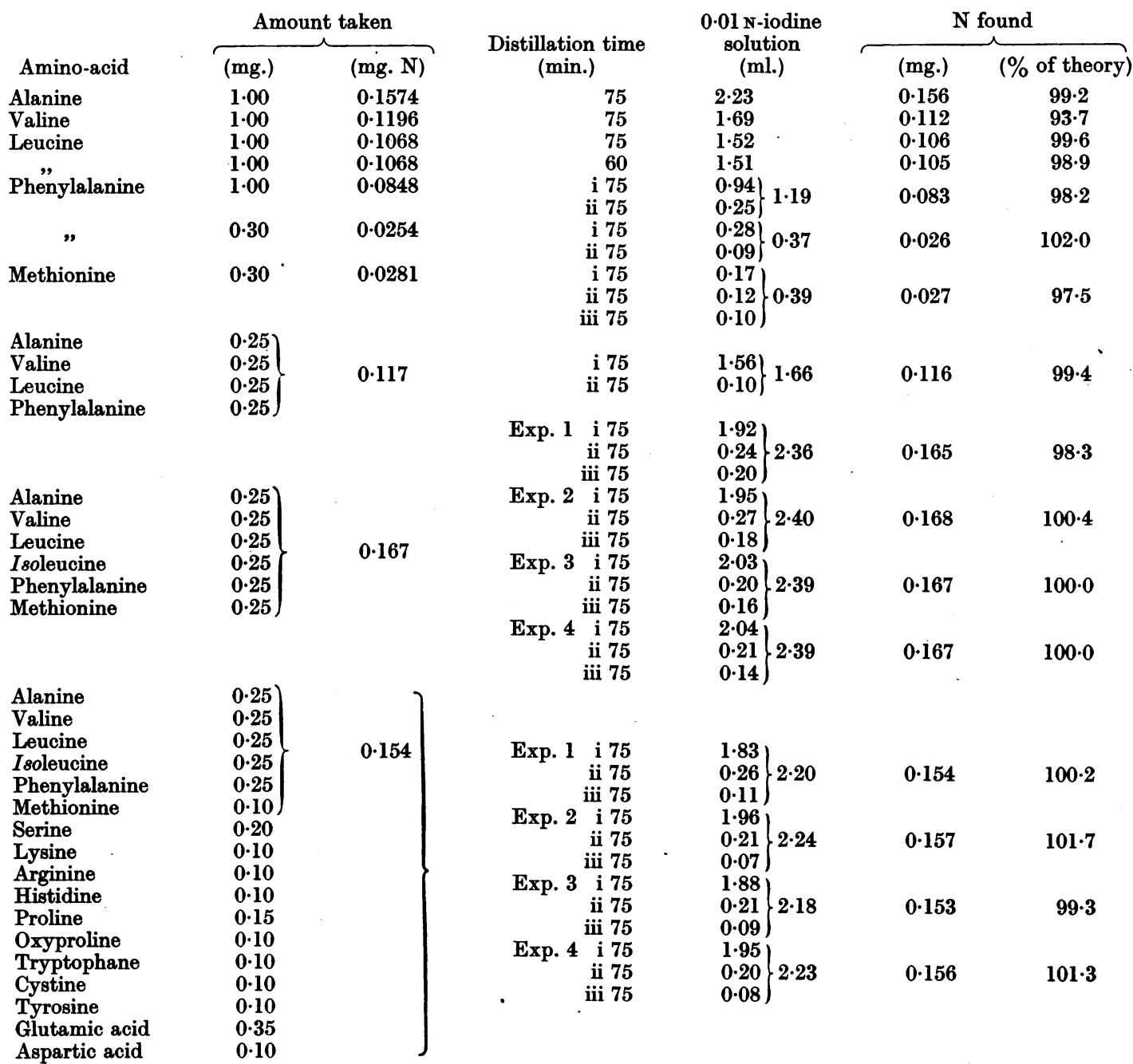

$1 \%(w / v)$ ninhydrin solution $(2 \cdot 0 \mathrm{ml}$.) was used in all experiments except the last, in which the solution was $2 \%$.

\section{Table 2. Replicate determinations of 'volatile aldehyde amino-acids' in casein hydrolysate}

(1 g. casein ( $=142.2 \mathrm{mg}$. N) was hydrolyzed with $10 \mathrm{ml}$. of conc. $\mathrm{HCl}$ for $6 \mathrm{hr}$. The hydrolysate $+100 \mathrm{ml}$. of water was evaporated in vacuo to a syrup. The residue was dissolved in water and made to $200 \mathrm{ml}$. A sample of $0.5 \mathrm{ml} .(=0.355 \mathrm{mg}$. N) was used for one determination.)

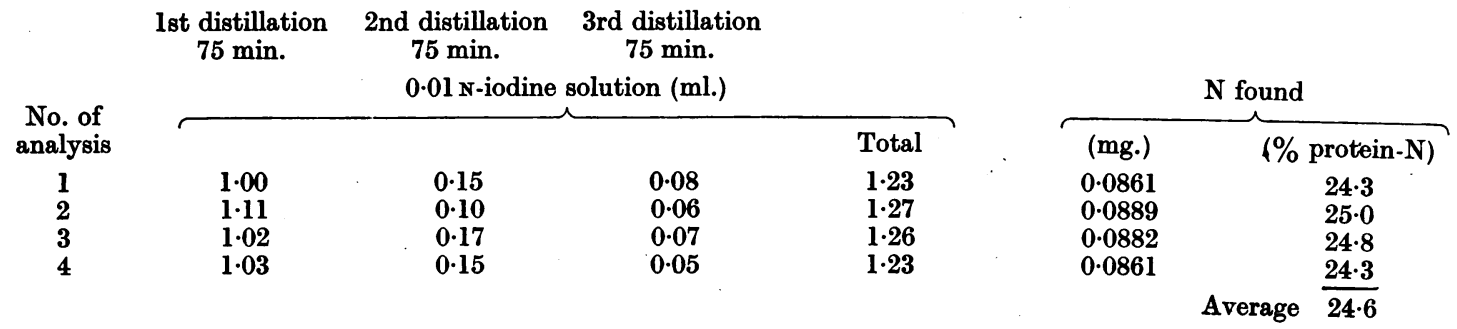




\section{SUMMARY}

1. A method based on the quantitative formation of volatile aldehydes from $\alpha$-alanine, valine, leucine, isoleucine and possibly other isomers, phenylalanine and methionine $\left(R . \mathrm{CH}\left(\mathrm{NH}_{2}\right) \cdot \mathrm{COOH} \rightarrow R . \mathrm{CHO}\right)$ has been used for the quantitative micro-determination of these amino-acids as a group ('volatile aldehyde amino-acids'). With other amino-acids found in proteins no formation of volatile aldehydes was detected under our experimental conditions.

2. Acetaldehyde can be determined separately from the mixture of aldehydes. Thus it is possible to determine by means of volatile aldehydes $(a)$ the above group of amino-acids, and (b) alanine. If phenylalanine and methionine are determined separately by specific methods, valine, leucine and isoleucine remain to be determined. Separate determination of the aldehydes formed from them has not yet been successful.

\title{
REFERENCES
}

Chibnall, A. C. (1946). J. int. Soc. Leath. Chem. 30, 1. Grassmann, W. \& von Arnim, K. (1934). Liebigs Ann. 510, 288.

Lieb, H. \& Zacherl, M. K. (1932). Hoppe-Seyl. Z. 211, 211. Mason, M. F. (1937). Proc. Soc. exp. Biol., N.Y., 37, 111. Mason, M. F. (1938). Biochem. J. 32, 719.

Roine, P. (1946). Suomen Kemistilehti, B, 19, 73.

Ruhemann, S. (1911). J. chem. Soc. 99, 792, 1486.

Van Slyke, D. D. \& Dillon, R. T. (1936). Proc. Soc. exp. Biol., N.Y., 34, 362.
Van Slyke, D. D. \& Dillon, R. T. (1938). C.R. Lab. Carlsberg, 22, 480.

Virtanen, A. I. \& Laine, T. (1938a). Nature, Lond., 142, 754.

Virtanen, A. I. \& Laine, T. (1938b). Skand. Arch. Physiol. 80, 392.

Virtanen, A. I., Laine, T. \& Toivonen, Toini (1940). Hoppe-Seyl. Z. 266, 193.

Virtanen, A. I. \& Rautanen, N. (1946). Suomen Kemistilehti, B, 19, 56.

\section{Experiments on the Localization and Nature of Tea Oxidase}

\author{
By LIEN PIAO LI (Fellow of the International Training Administration), \\ Tea Station (Meitan, Kweichow) of the National Agricultural Research Bureau, \\ Ministry of Agriculture and Forestry, Republic of China, \\ AND J. BONNER \\ William G. Kerckhoff Laboratories of the Biological Sciences, California Institute of Technology, \\ Pasadena, California
}

(Received 8 August 1946)

The conversion of green tea leaf into the product known as black tea involves the oxidation by leaf enzymes of the phenolic tannins of the leaf, the oxidation being initiated by the crushing of the wilted leaf. Ever since the recognition of the tea fermentation (as the process is generally known) as an enzymic oxidation, attempts have been made to identify the enzyme involved with one or another of the known oxidases. Early workers, notably Mann (1901), Bernard \& Welter (1911) and Manskaya (1935) have suggested identity of the tea fermentation enzyme with peroxidase, while tyrosinase (Potapov, 1934) and ascorbic acid oxidase have also been considered (Roberts, 1939a, b). Recent investigations carried on by Lamb \& Sreerangachar (1940) in Ceylon and by Roberts and Roberts \& Sarma (1938-42) in India have shown, however, that the tea enzyme is neither peroxidase nor ascorbic acid oxidase. Thus the simultaneous presence in the tea leaf of both peroxidase and the tea tannin does not suffice for fermentation. Ascorbic acid oxidase, if it is indeed present in the leaf at all, does not participate in the fermentation either directly or indirectly. According to Roberts (1942) tea leaf contains a cytochrome oxidase which is capable of oxidizing (presumably through the intermediary of cytochrome) tea tannin, catechol and $p$-phenylenediamine. The workers in India further believe that this same oxidase is the terminal oxidase of the normal respiration of the tea leaf. The views of Roberts and his group (1938-42) are mainly based on experiments carried out with whole minced leaves and these crude enzyme preparations always contained the tea tannin so that substrate specificity of the enzyme could not be clearly studied. The Ceylon workers, on the other hand, have shown (Lamb \& Sreerangachar, 1940; Sreerangachar, 1941, $1943 a, b, c, d)$ that the tea enzyme is a polyphenol 